\title{
Peningkatan Kapasitas Desa Tangguh Bencana
}

\author{
Rina Suryani Oktari* \\ * Fakultas Kedokteran Universitas Syiah Kuala, Banda Aceh \\ okta@unsyiah.ac.id
}

Submisi: 04 November 2017; Penerimaan: 26 Oktober 2018

Kata Kunci: Aceh Besar; desa tangguh bencana; ketahanan masyarakat; Lam Teungoh
Keywords: Aceh Besar; Lam Teungoh; disaster resilient village; resilience community
ABSTRAK Desa Lam Teungoh merupakan salah satu daerah yang terkena dampak tsunami terparah pada 2004 lalu. Dua belas tahun pascatsunami, beberapa fasilitas kesiapsiagaan tsunami yang ada di Desa Lam Teungoh, seperti rambu-rambu evakuasi dan informasi mengenai bahaya tsunami sudah dalam kondisi yang tidak layak. Kegiatan ini bertujuan untuk meningkatkan kapasitas dan ketangguhan aparatur dan masyarakat Desa Lam Teungoh dalam menghadapi bencana. Kegiatan ini dilaksanakan melalui metode survei partisipatif, ceramah, diskusi, praktik langsung, observasi, pendampingan, dan evaluasi. Pengembangan Desa Lam Teungoh sebagai desa tangguh bencana melibatkan beberapa mitra, termasuk Badan Penanggulangan Bencana Daerah Kabupaten Aceh Besar, pemerintah desa dan masyarakat, sekolah, serta lembaga swadaya masyarakat (LSM). Luaran dari kegiatan ini, antara lain, (a) meningkatnya pemahaman masyarakat tentang manajemen bencana; (b) teridentifikasinya ancaman, kerentanan, dan kapasitas Desa Lam Teungoh dalam menghadapi bencana; (c) tersusunnya Dokumen RPB, Peta Risiko Bencana, dan Peta Evakuasi Bencana Desa Lam Teungoh; (d) terbentuknya Forum Pengurangan Risiko Bencana Desa Lam Teungoh; dan (e) teridentifikasinya kebutuhan pelatihan kelompok ibu-ibu dan pemuda dalam meningkatkan perekonomian masyarakat Desa Lam Teungoh.

ABSTRACT Lam Teungoh village is one of the most affected areas during the tsunami 2004. Twelve years after the tsunami, most of the tsunami preparedness facilities in Lam Teungoh Village, such as evacuation signs and information on tsunami hazards are found in poor conditions. This activity aims to improve the capacity and resilience of apparatus and community of Lam Teungoh Village in the facing disaster. This activity is carried out through participatory survey methods, lectures, discussions, simulation, observation, mentoring, and evaluation. This activity involves several partners including Aceh Besar District Disaster Management Agency, village and community governments, schools, and nongovernmental organizations (NGOs). The outcomes of this activity include: i) Increased community understanding on disaster management, ii) Hazards, vulnerabilities, and capacities of Lam Teungoh Village on facing disaster are identified, iii) Disaster Management Plan Document, Disaster Risk Map, and Disaster Evacuation Map are formulated, iv) Disaster Risk Reduction Forum in Lam Teungoh Village is established, and v) Training needs of women and youth group in improving community economic status are identified. 


\section{PENDAHULUAN}

Indonesia merupakan negara kepulauan yang berdasarkan letak geografisnya dilalui oleh tiga lempeng tektonik, yaitu lempeng Eurasia, lempeng Indo-Australia, dan lempeng Samudra Pasifik. Kondisi tersebut menjadikan negara Indonesia sebagai "supermarket" bencana (Haryadi, 2012). Berbagai bencana yang terjadi di antaranya termasuk bencana geologi (gempa bumi, aktivitas vulkanik) dan bencana hidrologi (banjir, tanah longsor, tsunami). Berdasarkan data dari Emergency Events Database (EM-DAT), Indonesia termasuk lima besar negara yang rawan bencana dan termasuk sepuluh besar negara dengan angka kematian tertinggi akibat bencana pada 2014 (EMDAT, 2015; Guha-sapir et al., 2015).

Bencana tsunami pada 26 Desember 2004 yang melanda Aceh dan sekitarnya merupakan bencana dengan gempa terdahsyat ketiga di dunia sejak 1900. United States Geological Survey (USGS) menyebutkan jumlah korban dalam bencana ini mencapai 108.100 orang tewas, 127.700 hilang dan diduga tewas, serta 426.800 mengungsi (Dewey et al., 2007). Kabupaten Aceh Besar merupakan salah satu kabupaten yang secara geografis berbatasan dengan bibir pantai. Sekitar $10 \%$ desa di kabupaten ini merupakan daerah pesisir yang rawan terhadap bencana gempa bumi dan tsunami (BPS Aceh Besar, 2015). Desa Lam Teungoh yang berada di Kecamatan Peukan Bada, Kabupaten Aceh Besar merupakan salah satu daerah yang terkena dampak tsunami terparah pada 26 Desember 2004 lalu.

Tujuan kegiatan pengembangan Desa Tangguh Bencana ini adalah (a) melindungi masyarakat Desa Lam Teungoh dari dampak-dampak merugikan bencana; (b) meningkatkan peran serta masyarakat Desa Lam Teungoh, khususnya kelompok rentan, dalam pengelolaan sumber daya dalam rangka mengurangi risiko bencana; (c) meningkatkan kapasitas kelembagaan masyarakat Desa Lam Teungoh dalam pengelolaan sumber daya dan pemeliharaan kearifan lokal bagi pengurangan risiko bencana; (d) meningkatkan kapasitas aparatur Desa Lam Teungoh dalam memberikan dukungan sumber daya dan teknis bagi pengurangan risiko bencana; dan (e) meningkatkan kerja sama antara para pemangku kepentingan dalam PRB, pihak pemerintah daerah, sektor swasta, perguruan tinggi, LSM, organisasi masyarakat, dan kelompok-kelompok lainnya.

Aspek kebaruan (orisinalitas) dari kegiatan ini adalah pendekatan Participatory Action Research (PAR) yang digunakan untuk mengoptimalkan peran aktif masyarakat dalam pengembangan Desa Tangguh Bencana. Pendekatan PAR ini diharapkan dapat mendorong munculnya aksi transformatif, dimensi aksi sehingga memastikan adanya keterlibatan masyarakat yang tinggi sebagai pelaku (subjek) kegiatan (MacDonald, 2012; Stoudt et al., 2012)。

\section{MASALAH}

Permasalahan yang melatarbelakangi kegiatan ini adalah adanya kebutuhan untuk meningkatkan kesiapsiagaan Desa Lam Teungoh dalam menghadapi ancaman bencana, khususnya gempa bumi dan tsunami. Dua belas tahun pascatsunami, beberapa fasilitas kesiapsiagaan tsunami yang ada di Desa Lam Teungoh, seperti rambu-rambu evakuasi dan informasi mengenai bahaya tsunami ditemukan sudah dalam kondisi yang tidak layak.

Kondisi ini cukup mengkhawatirkan karena tingkat kesiapsiagaan seseorang bersifat dinamis, artinya dapat menurun setiap saat seiring berjalannya waktu (Hidayati et allo, 2006). 
Sebagai desa yang sangat rawan terhadap potensi tsunami, sudah seharusnya masyarakat di Desa Lam Teungoh memiliki tingkat kesiapsiagaan yang tinggi. Akan tetapi, berdasarkan hasil diskusi dengan aparatur desa setempat (Geuchik dan unsur Tuha Peut) diperoleh informasi bahwa selama ini di Desa Lam Teungoh belum pernah dilakukan program atau kegiatan yang bertujuan untuk meningkatkan kesiapsiagaan masyarakat dalam menghadapi bencana, khususnya gempa bumi dan tsunami.

\section{METODE}

Kegiatan yang dilaksanakan melalui pengembangan Desa Tangguh Bencana ini merupakan salah satu upaya dalam mengatasi permasalahan yang telah disebutkan di atas. Kegiatan ini dilaksanakan dengan metode survei partisipatif, ceramah, diskusi, praktik langsung, observasi, pendampingan, dan evaluasi. Adapun tahapan dalam pelaksanaan kegiatan pengembangan Desa Tangguh Bencana sebagai berikut: (1) Pengkajian Risiko Desa; (2) Perencanaan Penanggulangan Bencana (PB) dan Perencanaan Kontinjensi Desa; (3) Pembentukan Forum PRB Desa; (4) Peningkatan Kapasitas Warga dan Aparat dalam PB; (5) Pengintegrasian PRB ke dalam Rencana Pembangunan Desa dan Legalisasi, Pelaksanaan PRB di Desa; dan (6) Pemantauan, Evaluasi, dan Pelaporan Program di Tingkat Desa (BNPB, 2012).

Kegiatan pengembangan Desa Tangguh Bencana ini dilaksanakan selama tiga tahun, yakni mulai 2017-2019. Peta jalan (road map) terdiri atas tiga tahapan, yaitu (a) tahap persiapan dan inisiasi (2017), (b) tahap implementasi dan pendampingan (2018), dan (c) tahap penguatan serta pemonitoran (2019).

Selanjutnya, pengembangan Desa Tangguh Bencana ini melibatkan mitra, yakni aparatur dan masyarakat Desa Lam Teungoh, termasuk Lembaga Swadaya Masyarakat. Selain melibatkan Kepala Desa (Geuchik), Tuha Peut, dan tokoh masyarakat lainnya, kegiatan ini juga melibatkan Kelompok Ibu-Ibu Seulanga, Kelompok Pemuda Membangun Desa, serta Yayasan Khadam Indonesia yang telah banyak melakukan upaya pendampingan di masyarakat dalam meningkatkan kesiapsiagaan dalam menghadapi bencana. Keterlibatan wakil pemerintah desa/ kelurahan, wakil-wakil masyarakat, termasuk kelompok perempuan dan kelompok rentan menjadi salah satu indikator penting dalam pembentukan desa tangguh bencana. Pemerintah Kabupaten Aceh Besar, dalam hal ini Badan Penanggulangan Bencana Daerah (BPBD) Aceh Besar, juga memiliki komitmen dalam mengembangkan Desa Tangguh Bencana.

\section{HASIL DAN PEMBAHASAN}

Kegiatan yang telah dilakukan pada 2017 adalah (a) Pengkajian Risiko Desa, (b) Perencanaan PB dan Perencanaan Kontinjensi Desa, (c) Pembentukan Forum PRB Desa, dan (d) Peningkatan Kapasitas Masyarakat dan Aparat dalam PB.

\subsection{Pengkajian Risiko Desa}

Pada tahap awal pengkajian risiko bencana terlebih dahulu dilakukan workshop penyusunan profil Desa Lam Teungoh. Kegiatan penyusunan profil desa ini merupakan tahap pengantar ke dalam pembahasan program kegiatan Desa Tangguh Bencana. Berbagai informasi yang dikemukakan dalam kegiatan ini menjadi entry point dan memberikan 
pemahaman dasar untuk mengetahui kondisi lingkungan Desa Lam Teungoh dan masyarakatnya. Desa Lam Teungoh merupakan daerah yang pernah menjadi pelabuhan Indra Purwa pada masa lampau. Desa ini terletak di pinggir pesisir sehingga sumber mata pencaharian warga daerah sekitar adalah sebagai nelayan. Desa Lam Teungoh memiliki tiga dusun yang masing-masing dipimpin oleh kepala dusun. Dusun tersebut adalah Dusun Meunasah, Dusun Lam Teungoh, dan Dusun Lam Raya.

Desa Lam Teungoh merupakan salah satu dari 26 desa yang ada di Kecamatan Peukan Bada, Kabupaten Aceh Besar. Sebagian besar penduduk Desa Lam Teungoh bermata pencaharian sebagai petani sawah, petani tambak, pedagang, buruh, pertukangan, nelayan, dan pegawai pemerintahan. Perekonomian merupakan faktor yang dapat memengaruhi kesejahteraan dan kehidupan masyarakat. Masyarakat Desa Lam Teungoh memiliki banyak sektor usaha ekonomi, di antaranya usaha warung kopi, jual beli sembako/klontong, usaha peternakan, menjahit/bordir, pertukangan, dan lahan pertanian (sawah tadah hujan dan irigasi). Pendapatan rata-rata penduduk adalah Rp800.000,00— Rp2.000.000,00 per bulan.

Tabel 1. Penilaian Kerentanan Ancaman Gempa Bumi dan Tsunami di Desa Lam Teungoh

\begin{tabular}{|c|c|c|}
\hline Aspek & Asumsi Bentuk Risiko & Kelemahan Penyebab Risiko \\
\hline Manusia & $\begin{array}{l}\text { Pada } 2004 \text { (tsunami), jumlah } \\
\text { penduduk Desa Lam Teungoh sekitar } \\
900 \text { jiwa. } \\
\text { Yang akan datang, jumlah penduduk } \\
\text { sekitar } 320 \text { jiwa. } \\
\text { Diperkirakan jika terjadi gempa dan } \\
\text { tsunami, yang selamat berjumlah } 300 \\
\text { jiwa. }\end{array}$ & $\begin{array}{l}\text { Pada 2004: } \\
\text { Kapasitas dan kesiapan masyarakat tidak } \\
\text { ada sama sekali karena tidak pernah } \\
\text { mengalami dan kurangnya pengetahuan } \\
\text { tentang gempa/tsunami, termasuk cerita- } \\
\text { cerita rakyat tentang tsunami, padahal } \\
\text { hal tersebut sudah pernah terjadi di } \\
\text { tempat lain. } \\
\text { Pada masa yang akan datang, akan ada } \\
\text { korban yang dipengaruhi oleh kondisi } \\
\text { fisik rentan, seperti ibu hamil, lansia, } \\
\text { balita, disabilitas, orang sakit, serta } \\
\text { orang yang kurang mengetahui perihal } \\
\text { evakuasi diri. }\end{array}$ \\
\hline Ekonomi & $\begin{array}{l}\text { Pada } 2004 \text { (tsunami), mata } \\
\text { pencaharian masyarakat } 80 \% \text { sebagai } \\
\text { nelayan/petani. } \\
\text { Yang akan datang, } 50 \% \text { masyarakat } \\
\text { sudah sejahtera. } \\
\text { Diperkirakan masyarakat akan } \\
\text { semakin sejahtera sehingga akan } \\
\text { semakin siap menghadapi risiko } \\
\text { bencana gempa. }\end{array}$ & $\begin{array}{l}\text { Pendapatan masyarakat (nelayan/petani) } \\
\text { tergantung iklim/cuaca. }\end{array}$ \\
\hline Lingkungan & $\begin{array}{l}\text { Pada } 2004 \text { (tsunami), lingkungan } \\
\text { masih kotor karena (a) kesadaran } \\
\text { membuang sampah di tempat sampah } \\
\text { masih rendah dan (b) tidak semua } \\
\text { rumah memiliki jamban. } \\
\text { Yang akan datang: } \\
\text { kesadaran hidup bersih telah ada pada } \\
\text { masyarakat; } \\
\text { semua rumah telah memiliki jamban; } \\
\text { tingkat pengetahuan masyarakat } \\
\text { meningkat pada setiap aspek; }\end{array}$ & $\begin{array}{l}\text { Masih belum adanya pemisahan sampah } \\
\text { organik dan nonorganik. } \\
\text { Tidak adanya titik pembuangan sampah } \\
\text { sebelum dibuang ke TPA. }\end{array}$ \\
\hline
\end{tabular}


tahun 2004 tidak adanya petunjuk

jalur/tempat evakuasi; dan tidak adanya bangunan yang kokoh untuk gempa/tsunami.

Infrastruktur Tahun 2004, tidak ada petunjuk jalur/tempat evakuasi dan tidak ada bangunan yang kokoh untuk gempa/tsunami.

Yang akan datang: sudah ada petunjuk jalur/tempat evakuasi.

Sosial Sudah ada alarm gempa/tsunami Tahun 2004, sudah ada kelompok wirid, pengajian, klub bola, karang taruna, posyandu, dan PKK.
Belum ada bangunan yang ramah gempa/tsunami.

Belum ada partisipasi yang maksimal dari semua anggota.

Masih ada kerenggangan antarsesama masyarakat.

Sumber: data primer diolah (2017)

Setelah penyusunan profil desa, kegiatan dilanjutkan dengan melakukan analisis ancaman, kerentanan, dan kapasitas Desa Lam Teungoh dalam menghadapi bencana. Analisis ini bertujuan untuk mengidentifikasi atau mengenali (a) ancaman dan prioritas ancaman yang dipilih masyarakat, (b) hal-hal yang meningkatkan risiko dampak dari bencana dan tingkat kerentanan untuk tiap jenis ancaman yang ada, dan (c) kapasitas dengan melihat hubungan antara kerentanan dengan tiap jenis ancaman yang ada.

Penggalian pengetahuan dan pengalaman masyarakat tentang ancaman/bencana dilakukan di awal, yakni sebagai salah satu upaya membangun kesepahaman persepsi di antara masyarakat Desa Lam Teungoh. Berdasarkan diskusi yang dilakukan, masyarakat menyimpulkan ancaman yang berpotensi besar sebagai bencana di masyarakat. Berikut adalah hasil diskusi terkait peristiwa yang pernah terjadi dan berpeluang terjadi, yang kemudian disepakati oleh masyarakat sebagai ancaman bagi masyarakat Desa Lam Teungoh, yaitu gempa bumi, tsunami, serta angin kencang.

\section{Tabel 2. Penilaian Kapasitas terhadap Ancaman Gempa Bumi dan Tsunami di} Desa Lam Teungoh

\begin{tabular}{lll}
\hline \multicolumn{1}{c}{ Aspek } & & \multicolumn{1}{c}{ Kerentanan } \\
\hline Manusia & - & Perangkat Desa \\
& - & Posyandu \\
Ekonomi & - & PKK \\
& - & Pengajian \\
& - & Organisasi Kepemudaan \\
Insfratuktur & - & Nelayan \\
& - & Petani \\
Alam/lingkungan & - & Swasta \\
Sosial & - & PNS \\
& - & Tanggul Penahan Air Laut \\
& - & Polindes \\
& - & Jalur Evakuasi \\
& - & Gunung \\
& - & Gotong Royong \\
& & Kenduri Blang \\
& &
\end{tabular}

Sumber: data primer diolah (2017) 
Setelah analisis ancaman, kerentanan, dan kapasitas dilakukan, masyarakat melakukan pengkajian risiko bencana secara bersama-sama dalam rangka menentukan sifat dan tingkat risiko masing-masing ancaman yang ada di Desa Lam Teungoh dan menghasilkan gambaran menyeluruh dari semua ancaman dan risiko utama yang dihadapi masyarakat. Hasil kajian risiko bencana yang telah dilakukan menjadi bahan masukan dalam menyusun rencana evakuasi saat bencana terjadi. Kegiatan ini dilakukan melalui beberapa tahapan, yaitu penyusunan peta ancaman, identifikasi fasilitas umum di desa tempat masyarakat beraktivitas, penentuan tempat evakuasi, penentuan jalur evakuasi, dan penentuan strategi atau cara evakuasi. Kegiatan ini menghasilkan rancangan peta evakuasi yang akan dibuat secara formal untuk diperbanyak dan dipublikasikan di tempat-tempat strategis yang ada di tiap dusun di Desa Lam Teungoh.

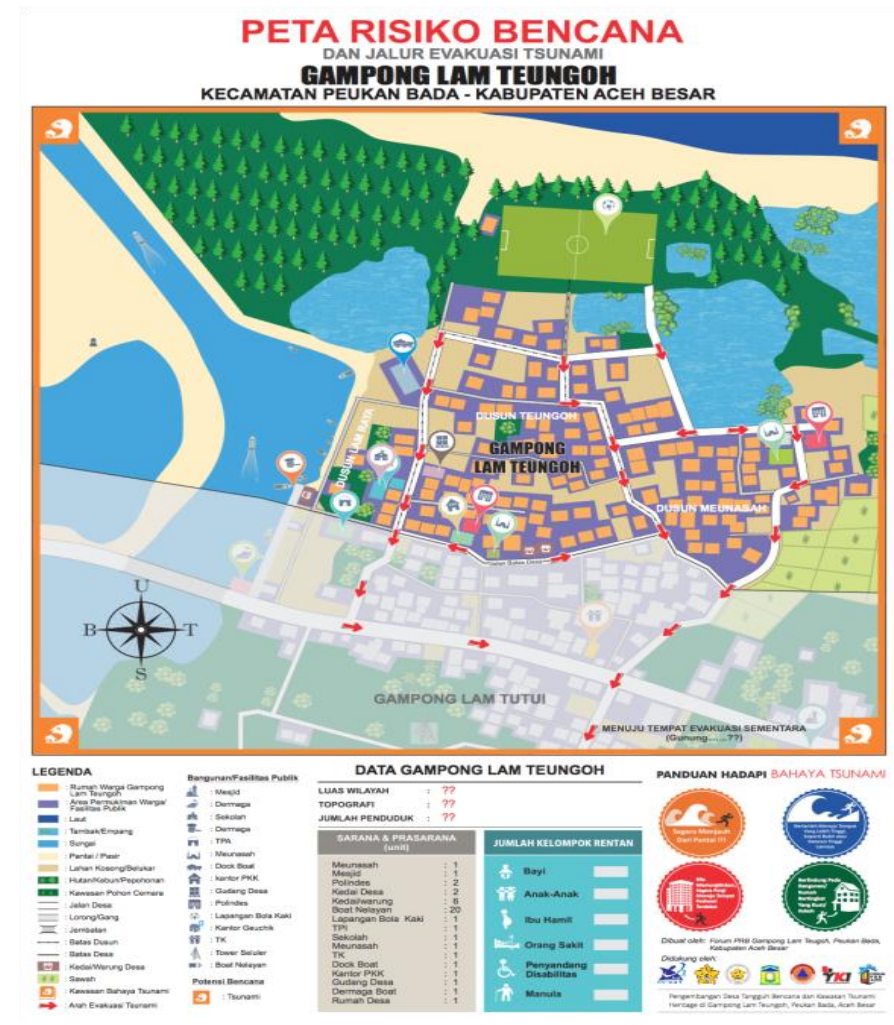

Sumber: data primer diolah (2017)

Gambar 1. Peta Risiko Bencana dan Peta Evakuasi Bencana Desa Lam Teungoh Berdasarkan Hasil Kajian Risiko Bencana Partisipatif

\subsection{Perencanaan PB dan Perencanaan Kontinjensi Desa}

Kegiatan ini bertujuan untuk membantu penyusunan dokumen Rencana Penanggulangan Bencana (RPB) Desa Lam Teungoh agar dapat diintegrasikan dengan Rencana Pembangunan Desa. Dokumen RPB ini disusun berdasarkan hasil kajian risiko bencana yang telah dilakukan sebelumnya.

Posisi dokumen RPB dengan RPJM Desa bukanlah dokumen yang terpisah. Dokumen RPB menjadi acuan bagi desa dalam menyusun program pembangunan yang terkait dengan penanggulangan bencana desa melalui proses perencanaan pembangunan di tingkat desa. Kegiatan ini menghasilkan dokumen rancangan RPB Desa Lam Teungoh. 


\subsection{Pembentukan Forum PRB Desa}

Pada kegiatan workshop pembentukan Forum Pengurangan Risiko Bencana (PRB) di Desa Lam Teungoh disepakati terbentuknya Struktur Organisasi Forum, termasuk personel dan tugas-tugasnya. Selain itu, dilakukan pemilihan pengurus dan penentuan struktur serta unit-unit (Pokja) yang diperlukan. Kepengurusan forum ini merepresentasikan semua unsur perwakilan masyarakat Desa Lam Teungoh, termasuk keterwakilan perempuan (lebih dari 30\%). Pemilihan pengurus dilakukan melalui musyawarah.

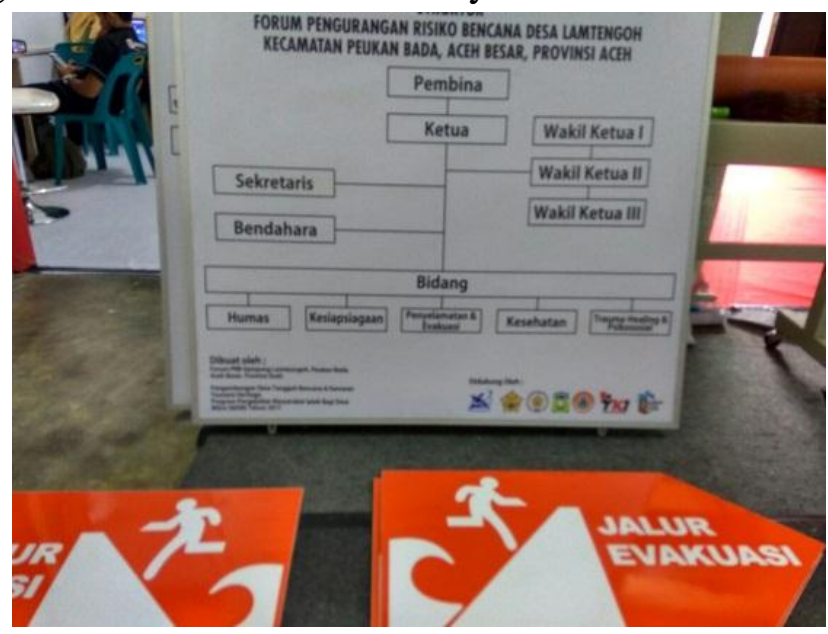

Sumber: Data primer diolah (2017)

Gambar 2. Struktur Forum Pengurangan Risiko Bencana di Desa Lam Teungoh

\subsection{Peningkatan Kapasitas Masyarakat dan Aparat dalam PB}

Dalam rangka pengembangan Desa Tangguh Bencana di Desa Lam Teungoh, beberapa upaya dilakukan untuk meningkatkan kapasitas masyarakat dan aparat dalam penanggulangan bencana. Sosialisasi Program Pengembangan Desa Tangguh Bencana bersama masyarakat dan tokoh masyarakat di Desa Lam Teungoh dilakukan Untuk memberikan gambaran tentang pelaksanaan program Destana serta memperoleh masukan dan saran guna menyusun strategi pelaksanaan program Destana di Desa Lam Teungoh. Selain itu, masyarakat Desa Lam Teungoh juga diberikan Pelatihan Participatory Action Research (PAR) untuk Mengenal Kearifan Lokal Pengurangan Risiko Bencana. Pelatihan Dasar Pengembangan Program Desa Tangguh Bencana juga diberikan kepada masyarakat dan aparatur Desa Lam Teungoh untuk memberikan pengetahuan tentang pengembangan program Desa Tangguh Bencana serta strategi yang dilakukan.

Pelatihan Konsep Dasar Manajemen Bencana juga diberikan kepada masyarakat dan aparatur Desa Lam Teungoh untuk memberikan pemahaman kepada masyarakat tentang konsep manajemen bencana, perubahan paradigma kebencanaan, serta program-program penanggulangan bencana. Pelatihan ini juga bertujuan untuk menyamakan persepsi masyarakat tentang konsep dan istilah yang digunakan dalam manajemen bencana.

\subsection{Rencana Tindak Lanjut}

Berdasarkan roadmap kegiatan yang telah disusun, rencana kegiatan yang akan dilaksanakan pada tahun kedua (2018) adalah Peningkatan Kapasitas Warga dan Aparat 
dalam PB, Pengintegrasian PRB ke dalam Rencana Pembangunan Desa dan Legalisasi, dan Pelaksanaan PRB di Desa. Selain kegiatan-kegiatan tersebut, pada tahun kedua juga akan dilaksanakan beberapa pelatihan untuk meningkatkan pendapatan masyarakat dan meningkatkan perekonomian Desa Lam Teungoh. Pelatihan -pelatihan tersebut akan difokuskan pada dua kelompok masyarakat berikut ini.

\subsubsection{Kelompok Ibu-Ibu Seulanga}

Berdasarkan hasil diskusi dengan ibu-ibu di Desa Lam Teungoh diketahui bahwa pelatihan yang dibutuhkan terkait dengan pengolahan ikan. Hal ini disebabkan letak strategis Desa Lam Teungoh yang berada di pesisir pantai sehingga terkenal sebagai daerah penghasil ikan. Selain itu, ibu-ibu di Desa Lam Teungoh membutuhkan pelatihan pembuatan kerajinan tangan yang produk-produknya diharapkan dapat dijual dan menambah pendapatan.

\subsubsection{Kelompok Pemuda Membangun Desa}

Beberapa pelatihan yang dibutuhkan oleh kelompok pemuda di Desa Lam Teungoh adalah pelatihan membuat pukat (jaring) untuk menangkap ikan di laut, pelatihan bahasa Inggris, dan pelatihan peningkatan kemampuan berkomunikasi sebagai bekal menjadi tour guide.

\section{SIMPULAN}

Kegiatan Peningkatan Kapasitas Desa Lam Teungoh, Kecamatan Peukan Bada, Aceh Besar dalam rangka Pengembangan Desa Tangguh Bencana yang dilakukan pada tahun pertama ini menghasilkan beberapa luaran, yakni peningkatan pemahaman masyarakat; tersusunnya Dokumen RPB, Peta Risiko Bencana, dan Peta Evakuasi Bencana Desa Lam Teungoh; serta terbentuknya Forum PRB Desa Lam Teungoh. Kegiatan ini juga mengidentifikasi kebutuhan pelatihan kelompok ibu-ibu dan pemuda dalam upaya meningkatkan perekonomian masyarakat Desa Lam Teungoh.

Dari hasil kegiatan ini disarankan perlunya keterlibatan multistakeholder dalam mendukung terwujudnya Desa Tangguh Bencana dan Kawasan Tsunami Heritage di Desa Lam Teungoh. Beberapa stakeholder yang perlu dilibatkan, yaitu Dinas Pariwisata, Palang Merah Indonesia (PMI), Media, dan Dunia Usaha.

\section{DAFTAR PUSTAKA}

BNPB. (2012). Peraturan Kepala Badan Nasional Penanggulangan Bencana No. 1 Tahun 2012 tentang Pedoman Umum Desa/ Kelurahan Tangguh Bencana.

BPS Aceh Besar (2015). Aceh Besar dalam Angka 2015. Aceh Besar: Jantho.

Dewey, J. W. et al. (2007). Seismicity Associated with the Sumatra-Andaman Islands Earthquake of 26 December 2004. Bulletin of the Seismological Society of America, 97(1A), S25-S 42. 
EMDAT, UNISDR (2015). Top Ten Number of Reported Disasters by Country. Retrieved from http://www.unisdr.org/filles/47804_2015 disastertrendsinfographic.pdf\&usg

Guha-Sapir D. et al. (2015). Annual Disaster Statistical Review 2014: The Numbers and Trends. CRED [Internet] 1-54. Retrieved from http://www.cred.be/sites/default/filles/ADSR_2011.pdf

Haryadi, W. (2012). Gempa Tektonik di Pulau Sumbawa dan Dampaknya Terhadap Bangunan Sipil (Suatu Kajian Geologis). 6:13.

Hidayati, D. et al. (2006). Kajian Kesiapsiagaan Masyarakat dalam Mengantisipasi Bencana Gempa Bumi dan Tsunami di Indonesia. Indonesia: LIPI-UNESCO/ISDR.

MacDonald, C. (2012). Understanding Participatory Action Research: A Qualitative Research Methodology Option. The Canadian Journal of Action Research, 13(2), 34-50.

Stoudt, B. G., Fox, M., \& Fine, M. (2012). Contesting Privilege with Critical Participatory Action Research. Journal of Social Issues, 68(1), 178-193. Retrieved from https://doi.org/10.1111/j。1540-4560.2011.01743.x) 